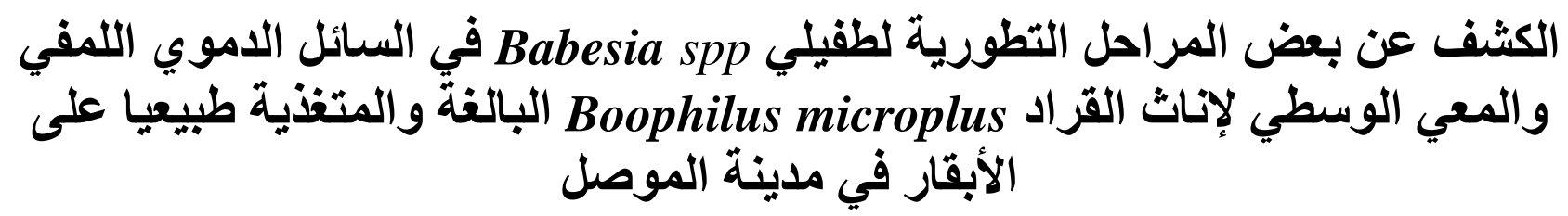

\author{
إيمان غانم سليمان وأحلام فتحي الطائي \\ فرع الأحياء المجهرية، كلية الطب البيطري، جامعة الموصل، الموصل، العراق

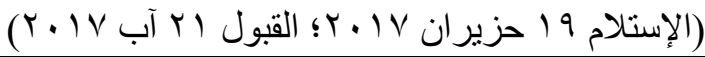

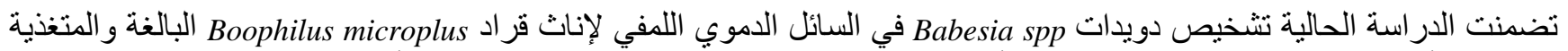

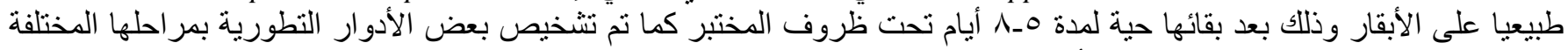

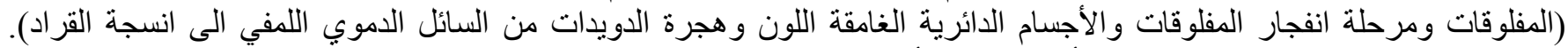

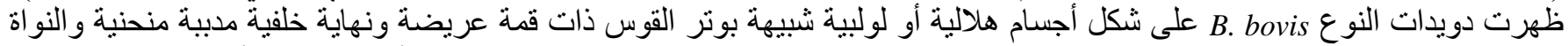

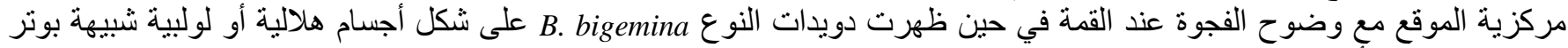

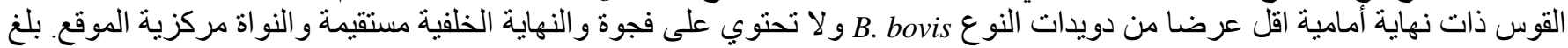

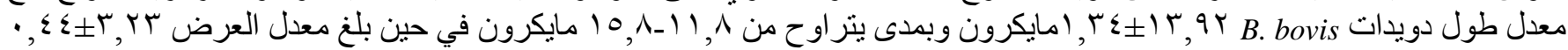

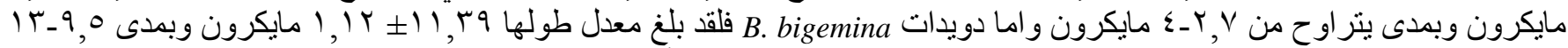

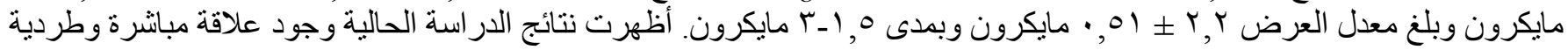

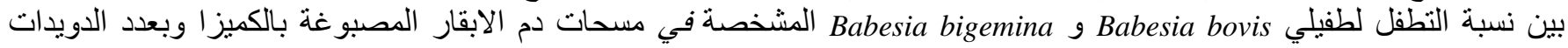

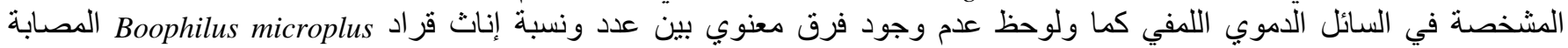

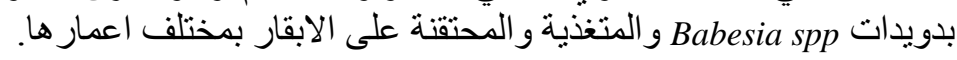

\title{
Detection the some developmental stages of Babesia spp in hemolymph and midgut of adult females of Boophilus microplus naturally on cattle in Mosul city
}

\author{
E.G. Suleiman and A.F. Altaee \\ Department of Microbiology, College of Veterinary Medicine, University of Mosul, Mosul, Iraq
}

\begin{abstract}
This study involved the detection of vermicules of Babesia spp in the hemolymph of Boophilus microplus adult females naturally fed on cattle after their remaining a live for 5 to 8 days under laboratory conditions and the detection of some developmental stages (schizonts, rupture of schizonts, small dark collar bodies and migration of vermicules from the hemolymph to different tissues of tick). Both vermicules of $B$. bovis and B. bigemina were diagnosed. The vermivules of $B$. bovis appeared as croissant or club-shaped bodies with a broad anterior ending and pointed posterior one and having a central nucleus and a vacuole in the anterior end with a curved or semi curved tail. The vermicules of B. bigemina had a croissant or club -shaped bodies with a lesser width in their anterior end than in B. bovis with no vacuole and with a straight tail. The average length of $B$. bovis was $13.92 \pm 1.34 \mu$ with a range of $11.8-15.8 \mu$ and average width of $3.23 \pm 0.44 \mu$ with a range of 2.7$4 \mu$. The average length of $B$. bigemina was $11.39 \pm 1.12 \mu$ with a range of $9.5-13 \mu$ and average width of $2.2 \pm 0.51 \mu$ with a range of $1.5-3 \mu$. The results of current study revealed that their was a direct and proportional relationship between the parasitemia of B. bovis and B. bigemina in cattle blood smears and the number of vermicules in the hemolymph of female of Boophilus
\end{abstract}


microplus. No significant differences were noticed between (number and percentage of Boophilus microplus females) infected with vermicules of Babesia spp at different aged cattle.

Available online at http://www.vetmedmosul.org/ijvs

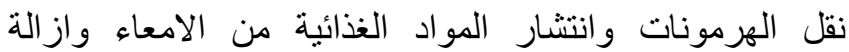

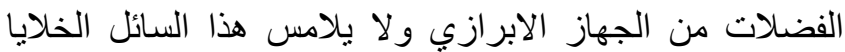

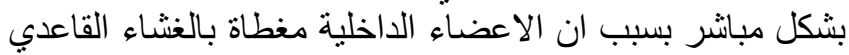
( Basement membrane) الدموي اللمفي اختبار اقتصادي و تقنية سريعة لتحديد الممرضات

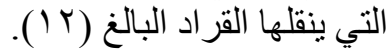

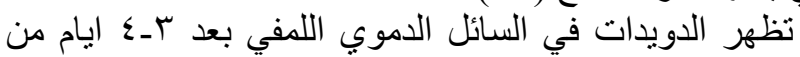

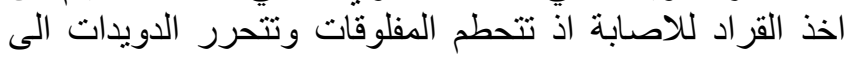

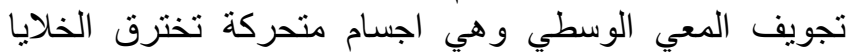

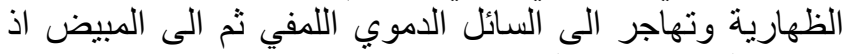

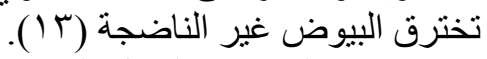

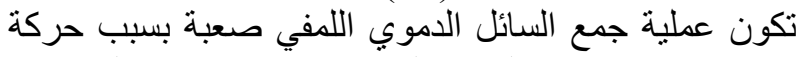

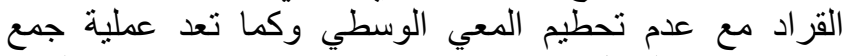
وفحص هذا السائل شيء اساسي في تحديد العيد دور الصابة القرادية

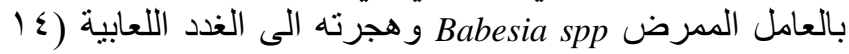

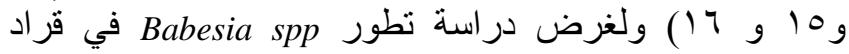
Boophilus microplus

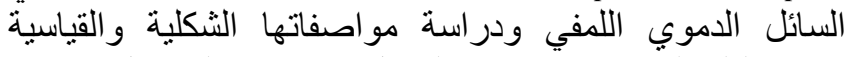
ونظرا لقلة الدراسات في هذا المجال في مدينة الموصل اجريت

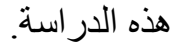

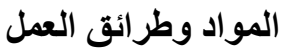

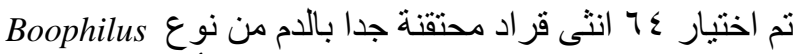
microplus

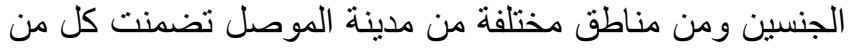

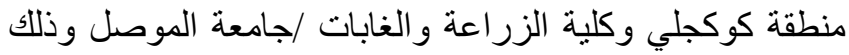

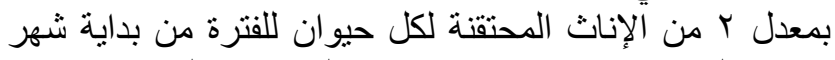

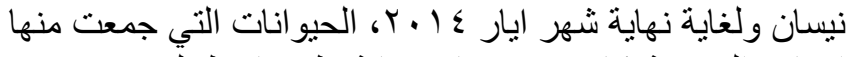

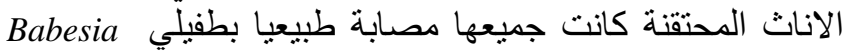

.Babesia bigemina govis وضعت اناث القراد الماخوذة من كل حيوان في عبوات

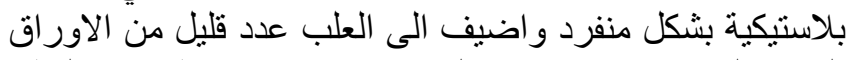

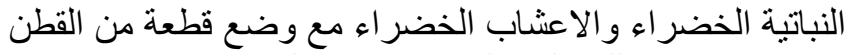

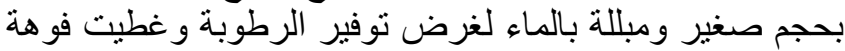

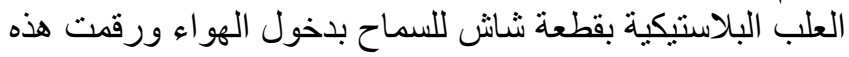

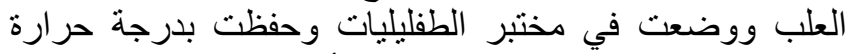

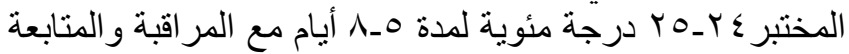

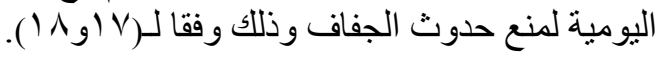

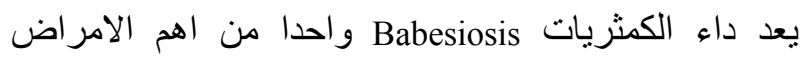

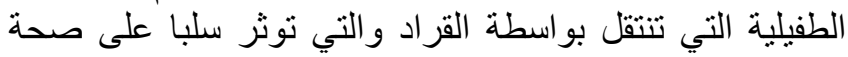

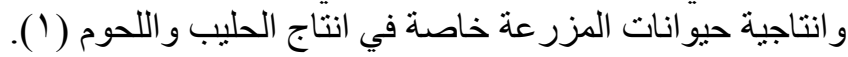

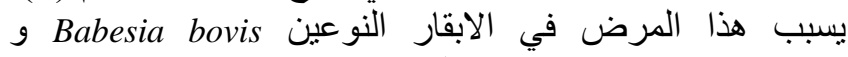
Babesia bigemina

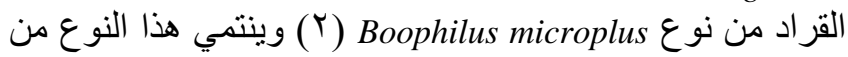
القر اد الى مجموعة القراد ذو المضيف الواحد (r)host يعتمد التمبيز بين انواع Babesia على الثكل والخصوصية للمضيف وطريقة الانتقال ونو أنو القر اد الناقل و المعلومات الو الوبائية

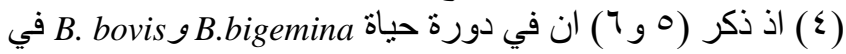

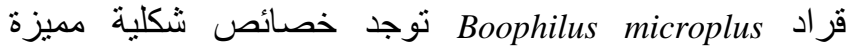

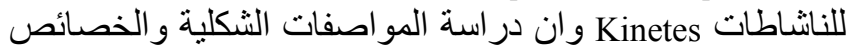

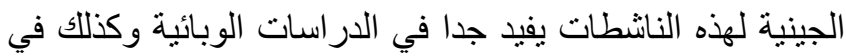

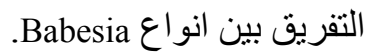

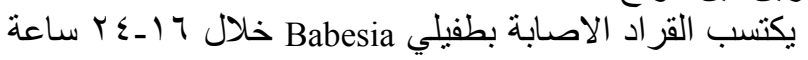

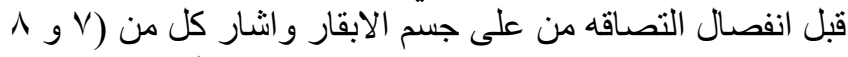

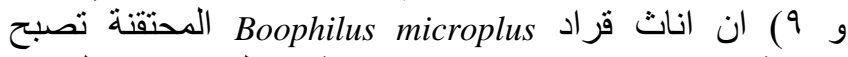

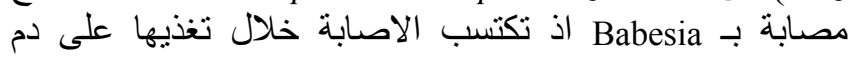

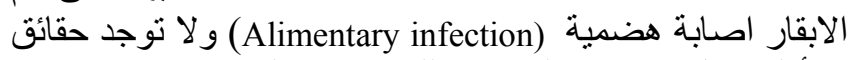
او أدلة حول الاصنابة الهضمية لليرقات او الحوريات و انما بعتقد

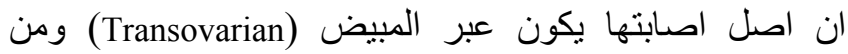
مرحلة الى مرحلة (Transtadial).

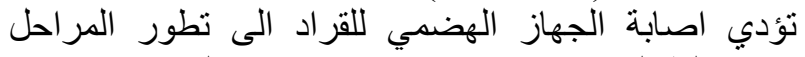
النموذجية لطفيلي B. bigemina في محتوى المعي (Gut)

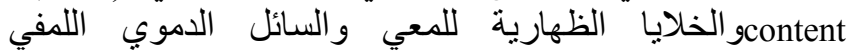
ويحدث التكاثر الجنسي في القراد الناقل وتتنكون (Hemolymph)

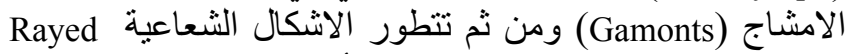
وتبدأ مرحلة التكاثر اللاجنسي (Koch's strahlenkoper) الذي ينتج عنه اجسام كوبية الثكل متحركة ( Motile club shaped (bodies ) تسمى الدويدات (Vermicules) او الناشطات (Kinetes) والتي تهاجر الى مختلف الانسجة في جسم القراد وتمتاز هذات التهات التهات

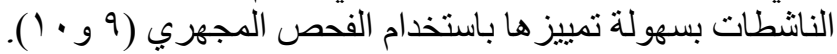

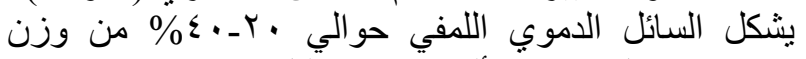

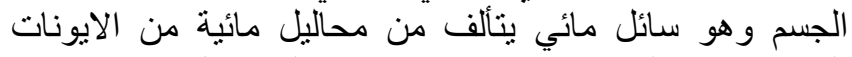

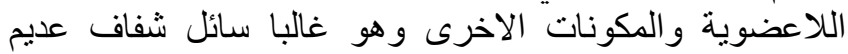

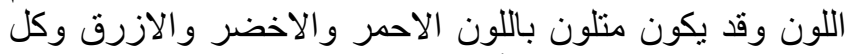
التبادلات الكيمبائية بين الأعضاء تلأنجز الأني واسطة هذا السائل مثل وكل 
جدول (1) يبين عدد ونسبة اناث القراد Boophilus microplus

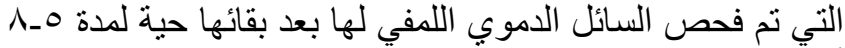
أيام في المختبر و المصابة بدويدات Babesia spp

\begin{tabular}{|c|c|c|}
\hline 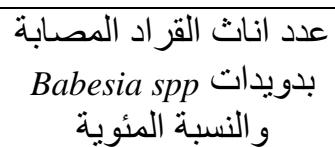 & $\begin{array}{c}\text { عدد اناث قر اد } \\
\text { Boophilus } \\
\text { microplus }\end{array}$ & 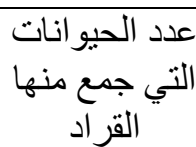 \\
\hline$(\varepsilon \wedge, \varepsilon \Gamma) \Gamma$ & $7 \varepsilon$ & Tr \\
\hline
\end{tabular}

جدول (ץ) يبين عدد ونسبة اناث قراد Boophilus microplus

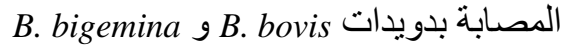

\begin{tabular}{|c|c|c|}
\hline عدد اناث القراد & عدد اناث القر اد & عدد اناث قر اد \\
\hline المصابة & المصنابة & Boophilus microplus \\
\hline بدويدات & بدويدات & المصـابة بدويدات \\
\hline $\begin{array}{l}\text { B. bigemina } \\
\text { والنسبة المئوية }\end{array}$ & $\begin{array}{c}\text { B. bovis } \\
\text { والمئوية النسبة }\end{array}$ & Babesia spp \\
\hline$(T \varepsilon, 01) Y$. & $(V \cdot, 97) Y r$ & I \\
\hline
\end{tabular}

تم في هذه الدراسة وصف شكل Babesia spp وقياس الطول

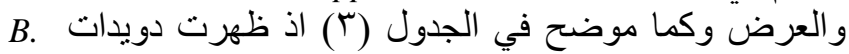
bovis

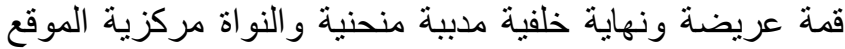

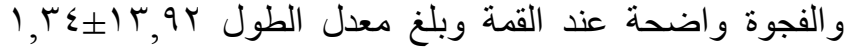

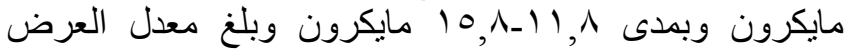

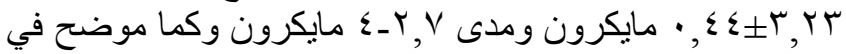

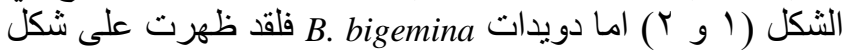

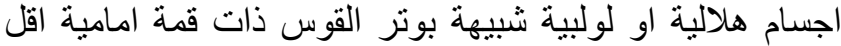

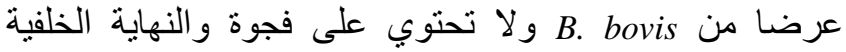
مستقيمة اكثر من منحنية والنواة مركزية الموقع وبلغ معدل

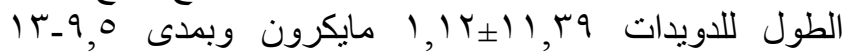

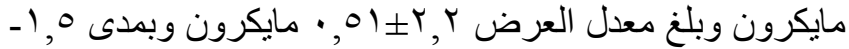

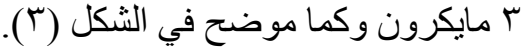

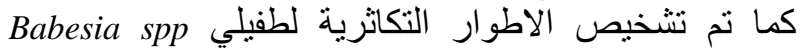

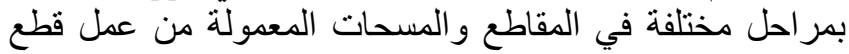

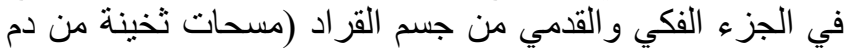

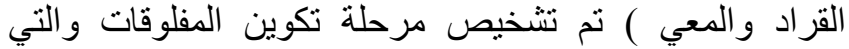
لوحظت باعداد كبيرة وتحتوي على عدئ عدد كبير من الاجسام

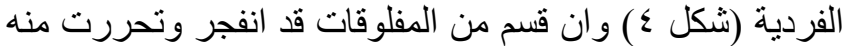

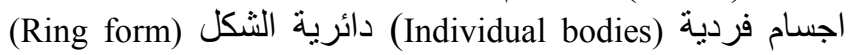
غامقة اللون (شكل 0) والتي تتحول الى مفلوقات بالانقسام

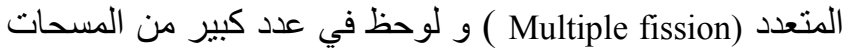
المعمولة هجرة الدويدات من السائل الدموي اللمفي الى الى انسجة

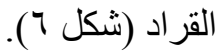

طريقة جمع السائل الاموي اللمفي

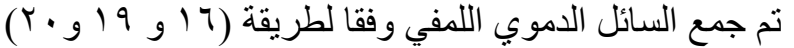

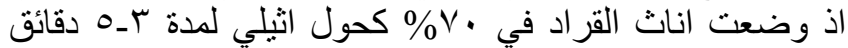

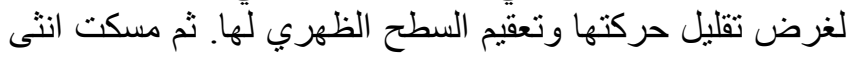

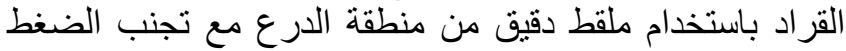

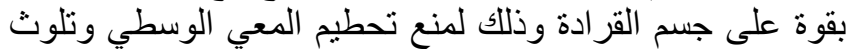

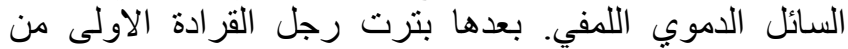

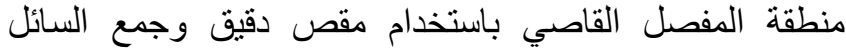

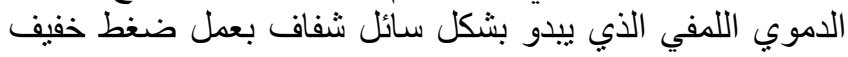

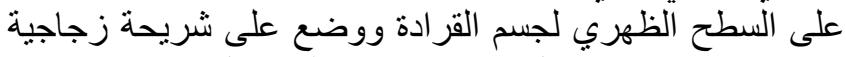
نظيفة وقد تم قطع ارجل اخرى اضافة الى عمل ثقب في منطقة

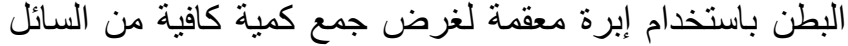

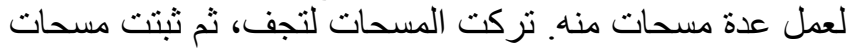

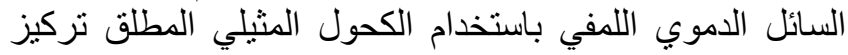

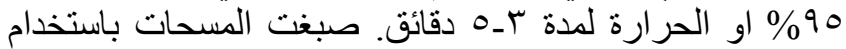

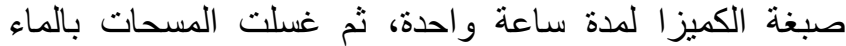
المقطر وتركت لتجف وثم فحصت مجهريا باستخدام العدسة الزيتية ( • (X) وتم استخدام المقياس العيني وذلك لقياس ابعاد الدويدات المشخصة.

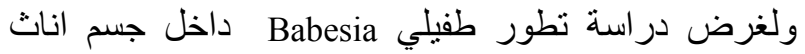

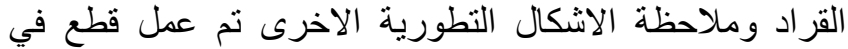

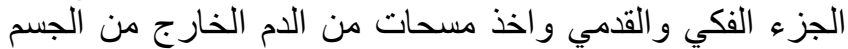

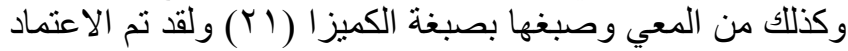

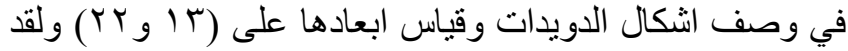
تcular ) تم قياس ابعاد الدويدات باستخدام المقياس العيني والقد حلات نتائج البحث إحصائيا لاستخر اج المعدل

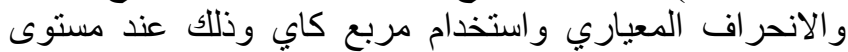

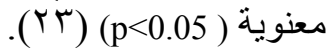

النتائج

تبين من خلال فحص السائل الدموي اللمفي لاناث القراد

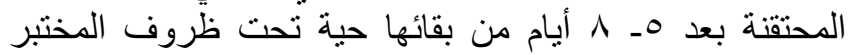

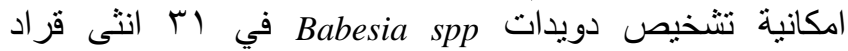

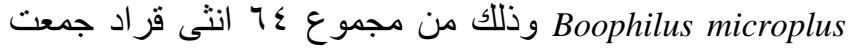

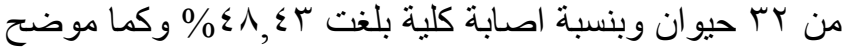
في الجدول (1) - (1)

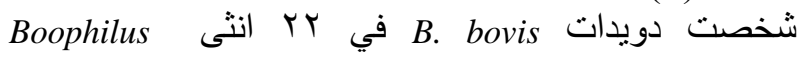

B. microplus bigemina

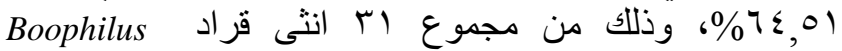
microplus

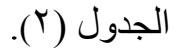


جدول (ץ) يوضح المقارنة بين المو اصفات الثكلية والقياسية لدويدات Babesia spp

\begin{tabular}{|c|c|c|c|c|c|}
\hline \multicolumn{2}{|r|}{ العرض Mm } & \multicolumn{2}{|c|}{ الطول Mm } & \multirow[b]{2}{*}{ المو اصفات الثكلية } & \multirow[b]{2}{*}{ الطفيلي } \\
\hline المدى & 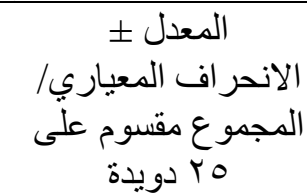 & المدى & 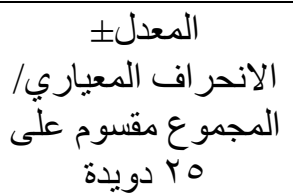 & & \\
\hline$\varepsilon-Y, V$ & $\cdot, \varepsilon \leqslant \pm r, r r$ & $10, \Lambda_{-} \mid 1, \wedge$ & $1, r \varepsilon \pm 1 r, q r$ & 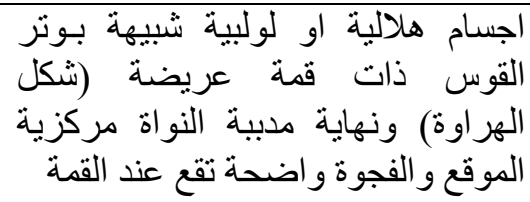 & 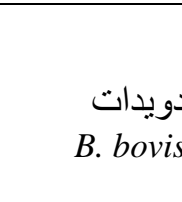 \\
\hline$r-1,0$ & $\cdot, 01 \pm r, r$ & $1 r_{-} 9,0$ & $\left.1,1 r_{ \pm}\right), r_{q}$ & 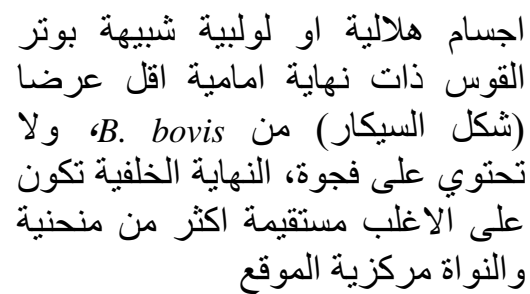 & B. bigemina \\
\hline
\end{tabular}

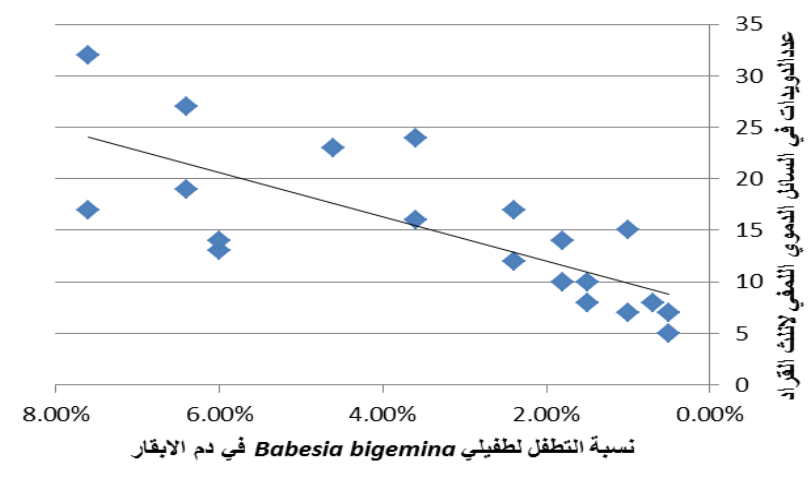

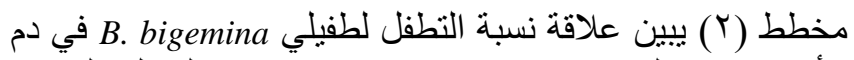

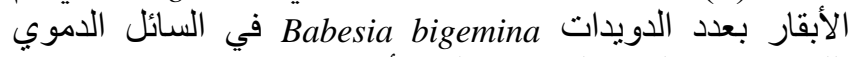
اللمفي لاناث القر اد المتغذية على الأبقار.

اظهرت نتائج الدراسة الحالية ان اصابة اناث القر اد المتغذية

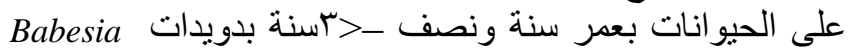

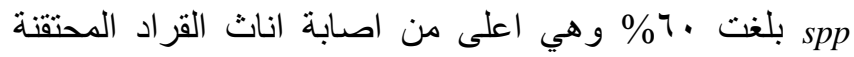

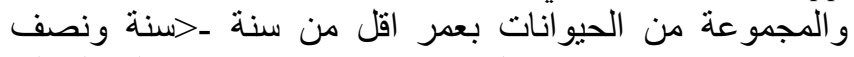

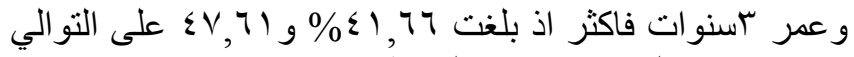

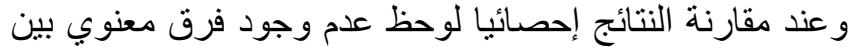

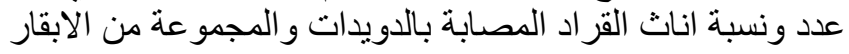

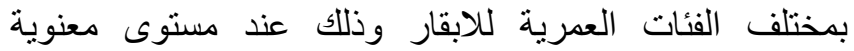

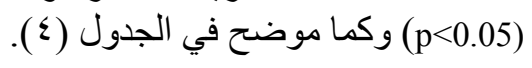

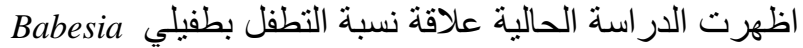

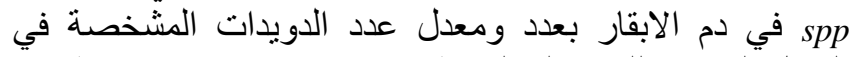
السائل الاموي اللمفي فلقد لوحظ انه توجد ودئ علاقة مباثرة وطردية

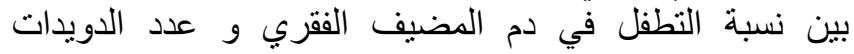

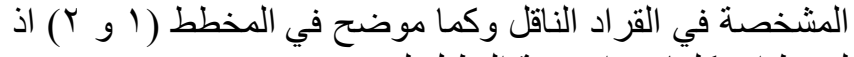

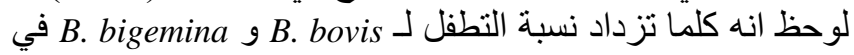
دم المضيف الفقري يزداد عدد الدويدات في السائل الدموي اللمفي

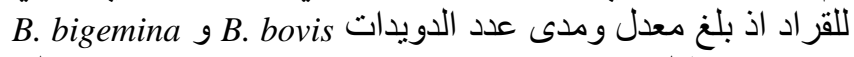

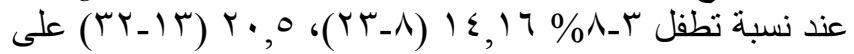

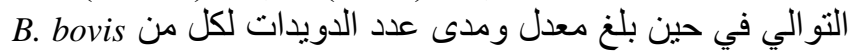

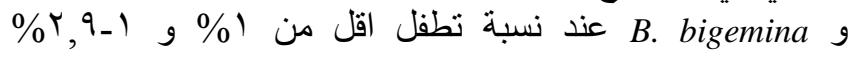

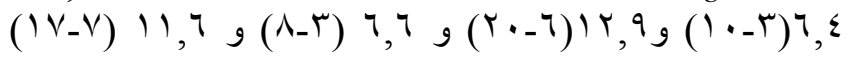
على التو الي.

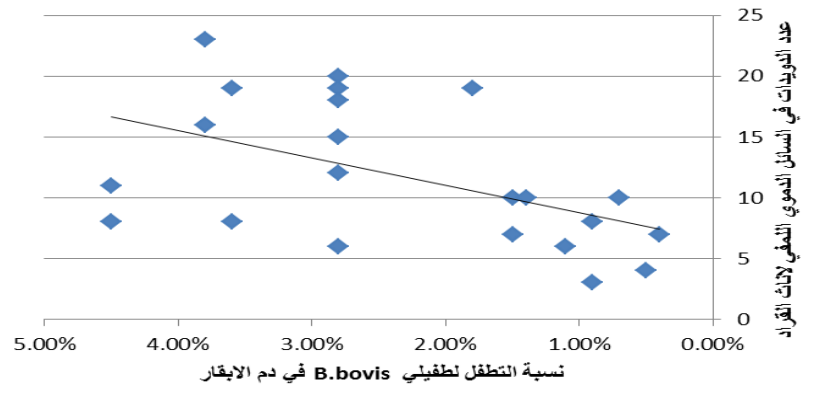

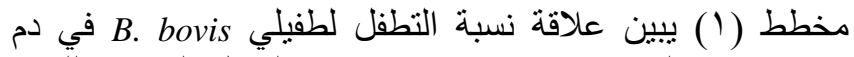

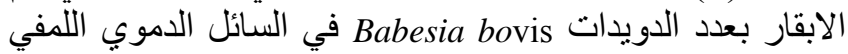
لإناث القراد المتغذية على الابقار. 


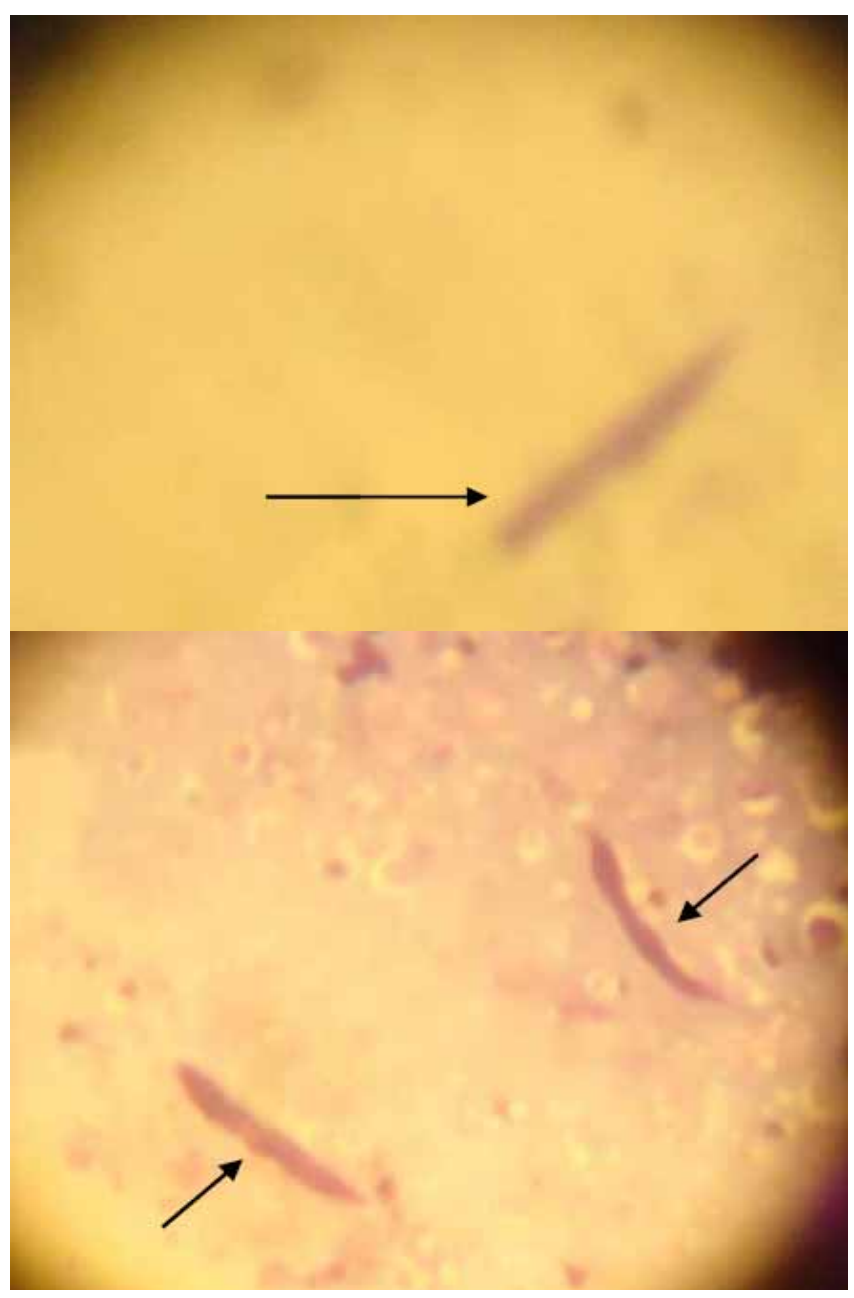

شكل (r) يوضح دويدة Vermicule لطفيلي B.bigemina في

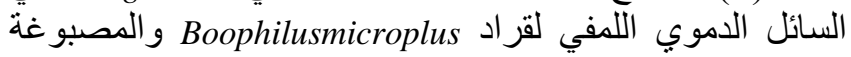

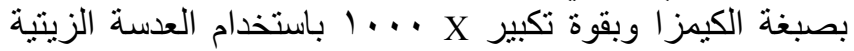

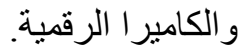

جدول (§) يوضح علاقة عدد ونسبة اناث قراد Boophsilus المصابة بدويدات Babesia spp بعمر الابقار

\begin{tabular}{|c|c|c|}
\hline 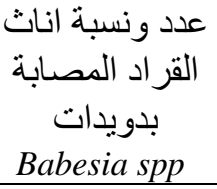 & عدد اناث القر اد & العمر \\
\hline $\begin{array}{c}(51,77)^{0} \\
(7 \cdot)^{7}\end{array}$ & $\begin{array}{ll} & 1 \\
& 1 \\
a & 1 .\end{array}$ & 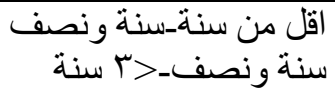 \\
\hline$\left(\sum V, 7\right)(1) r$. & $a \leqslant r$ & س سنة فأكثر \\
\hline$(\varepsilon \wedge, \varepsilon \Gamma) \Gamma$ & $7 \varepsilon$ & المجموع \\
\hline
\end{tabular}

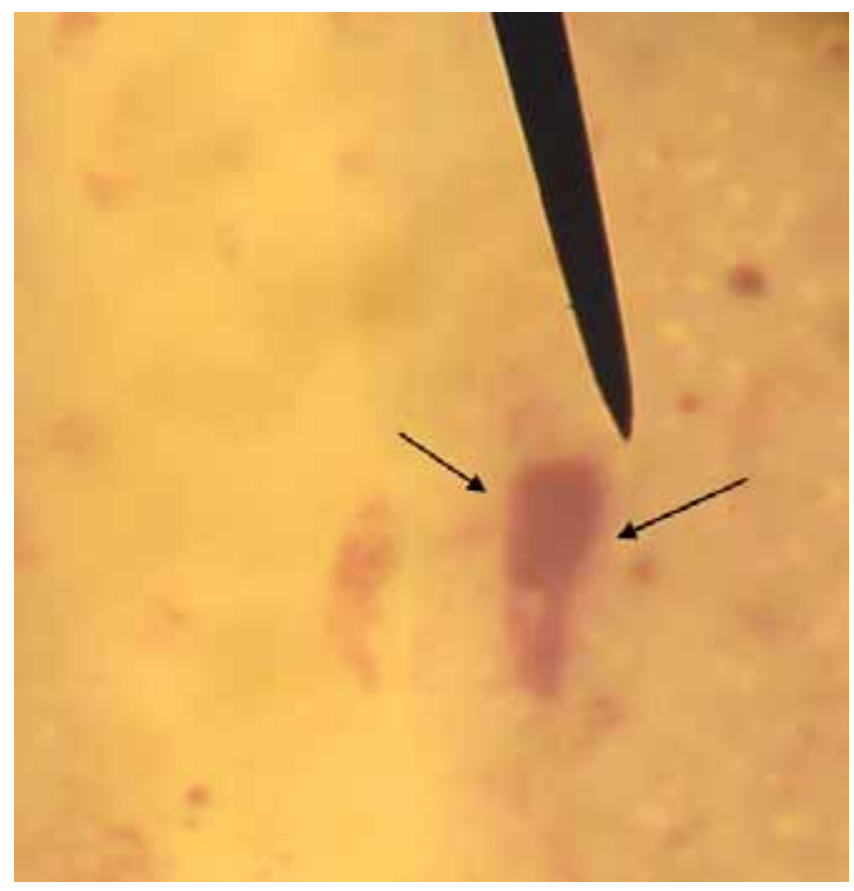

شكل (1) يوضح دويدة B. bovis و التي تمتاز بالقمة الامامية

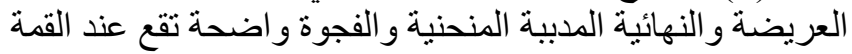
الامامية وبقوة تكبير X X . . . باستخدام العدسة الزيتية والكاميرا

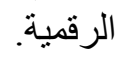

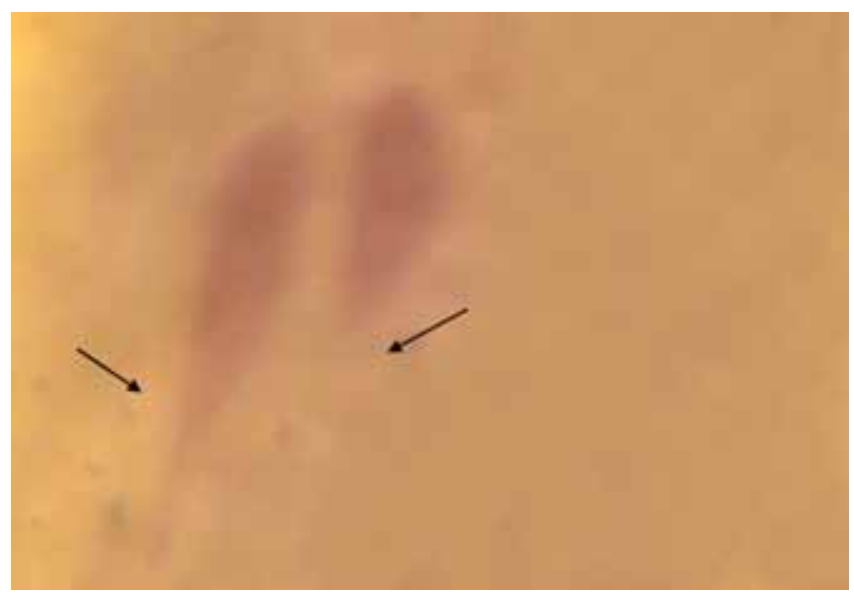

شكل (r) يوضح التباين في طول دويدات Vermicules لطفيلي

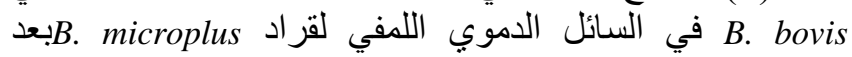

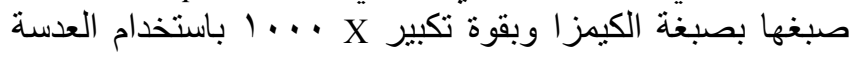
الزيتية و الكامير ا الرقمية. 


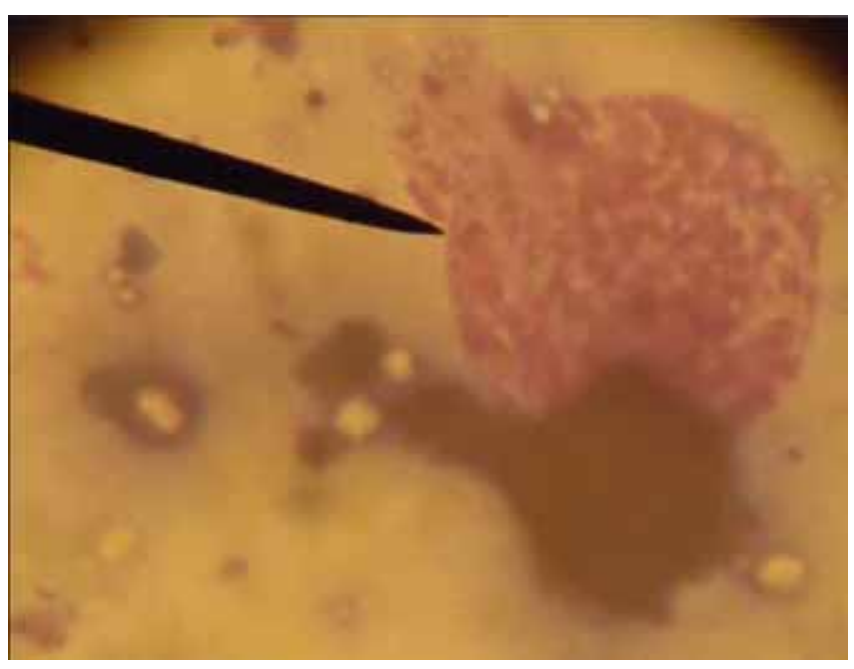

شكل (0) يوضح مرحلة انفجار المفلوق schizont وتتحرر

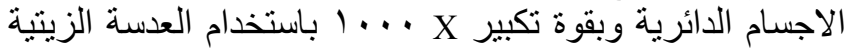

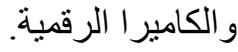

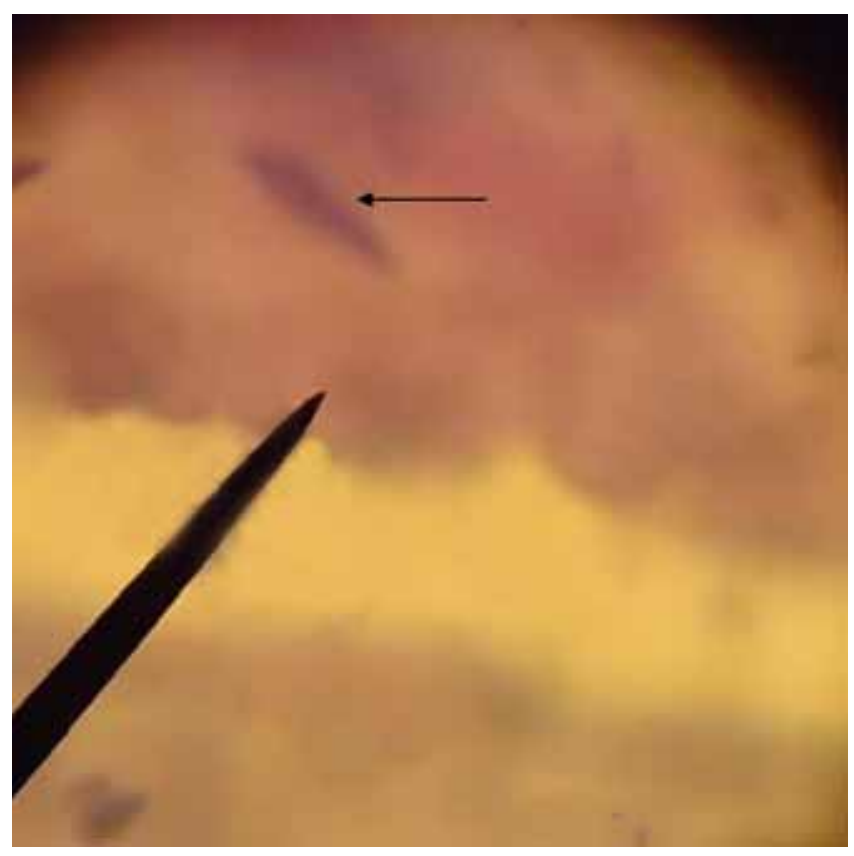

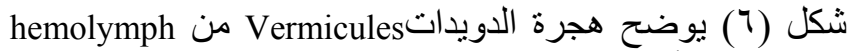

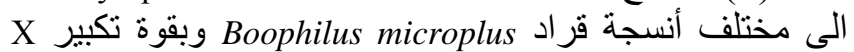
. . . . . باستخدام العدسة الزيتية و الكامير ا الرقمية.

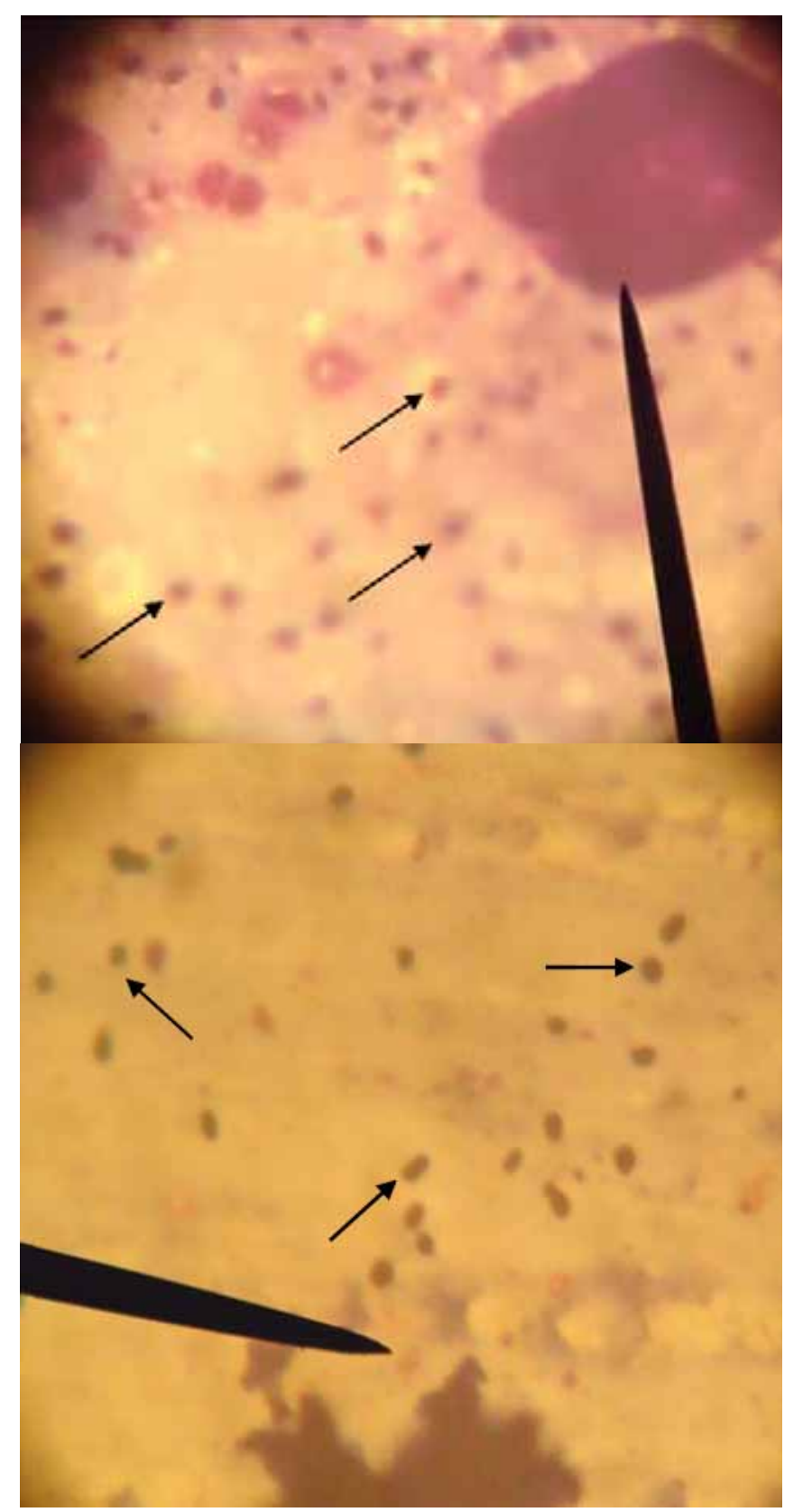

شكل (ع) يوضح الاطوار التكاثرية (مرحلة تكوين المفلوقات الاترية

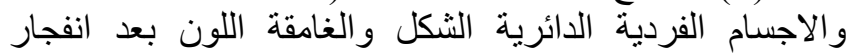

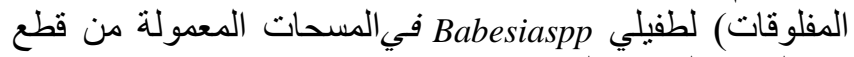

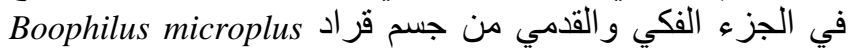
تكبير X X . . . باستخدام العدسة الزيتية و الكامير ا الرقمية. 
الهضمية وذكر (V) بان الحوريات و البالغات ميزت كأدوار ناقلة

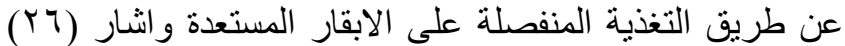

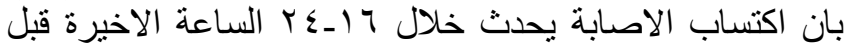

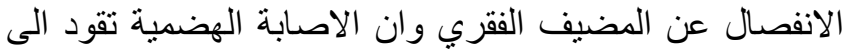

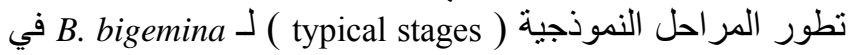

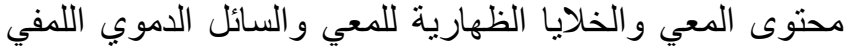

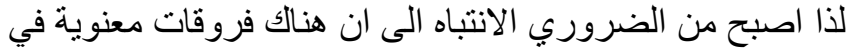

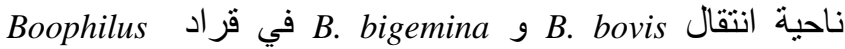
microplus

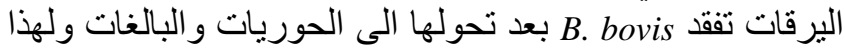

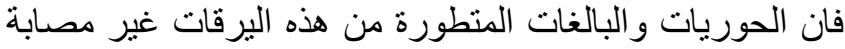

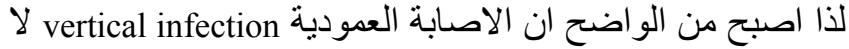

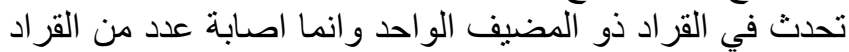

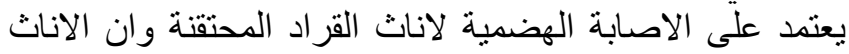

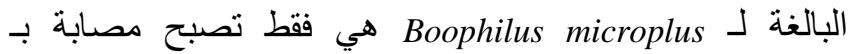

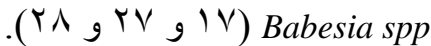
و و عند مقارنة المو اصفات الثكلية والقياسية لدويدات Babesia spp

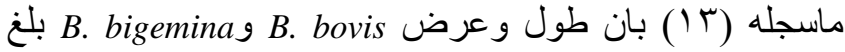

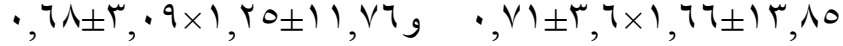

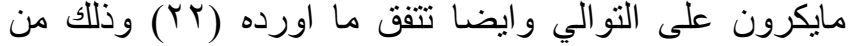

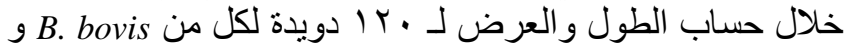

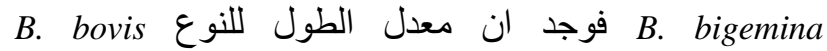

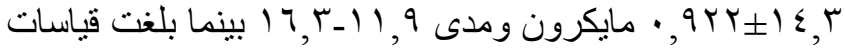
النوع آن ع B. bigemina

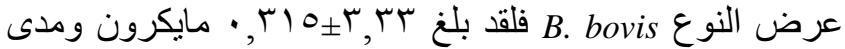

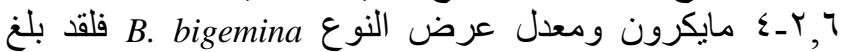
\&

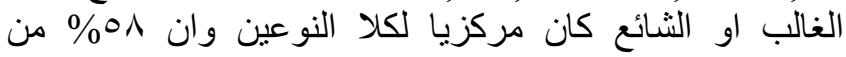

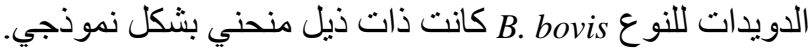

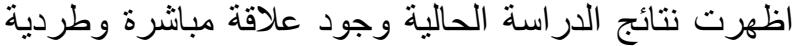

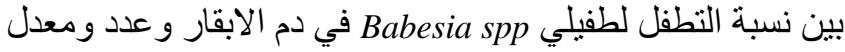

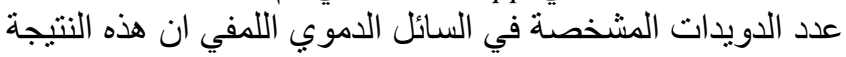

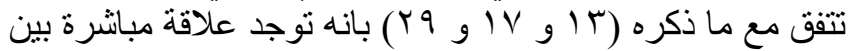
نسبة التطفل ووقت سقوط القراد واد ومستوى تطور Babesia في

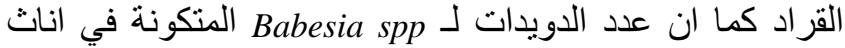

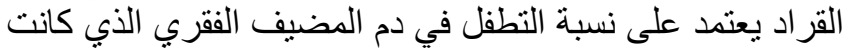

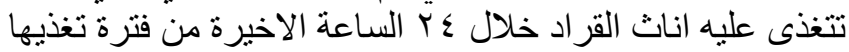

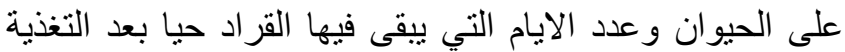

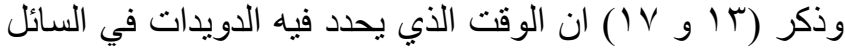

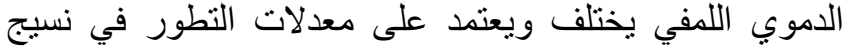

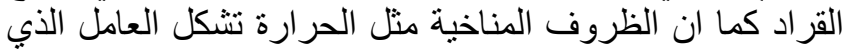

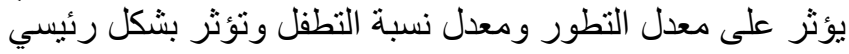

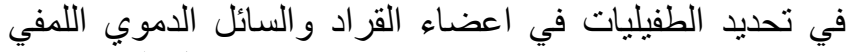
واورد (0 و 7) ان تطور Babesia في جميع مر احل القراد يكون التري

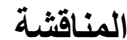

اتضح في هذه الدراسة تشخيص دويدات Babesia spp في التي التيات

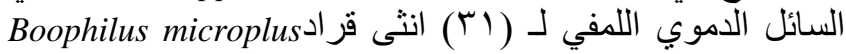

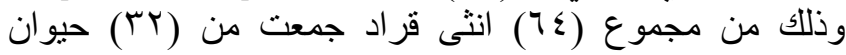

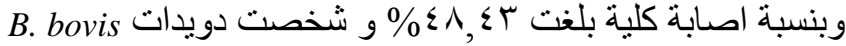

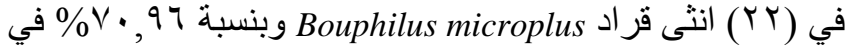

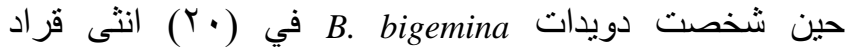
Boophilus microplus

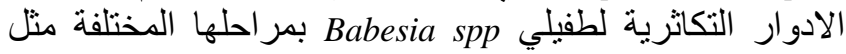

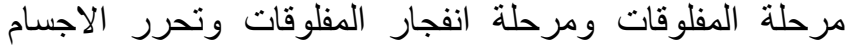
الفردية منها ومرحلة هجرة الدويدات من السائل الدموي اللمفي

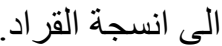
ان هذه النتيجة تتفق مع ما ذكره كل من (10 و و ـ الـ ) بان تقنية

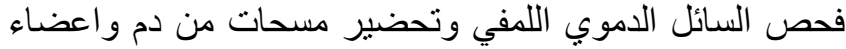

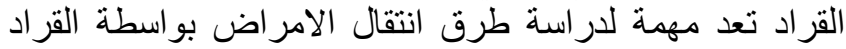

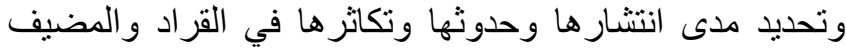

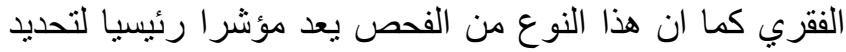

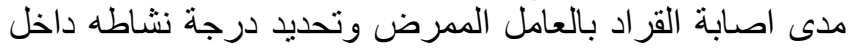

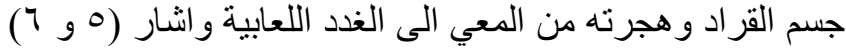

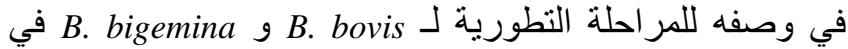

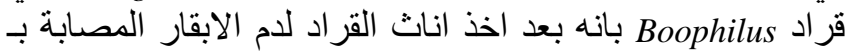

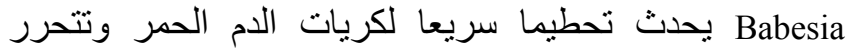

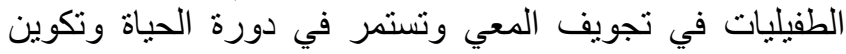
المر احل الجنسية.

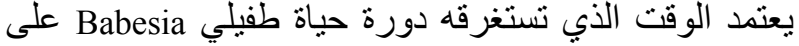

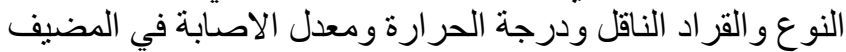

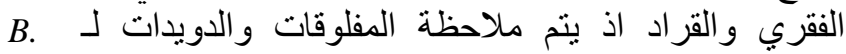

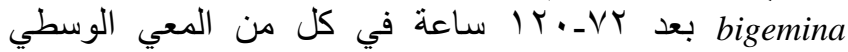
والسائل الدموي اللمفي وانابيب مالبيجي Malpighina tubules

توجد صعوبة في تمبيز الادوار الجنسية المبكرة والادوار

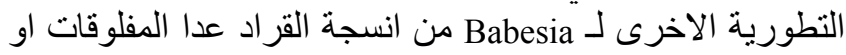

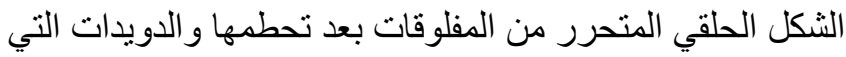

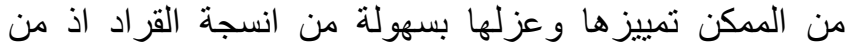

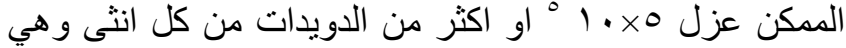

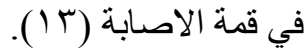

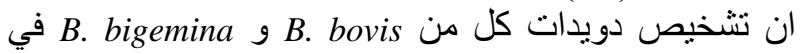

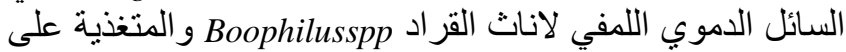

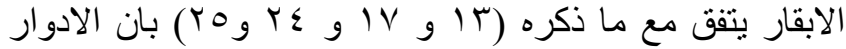

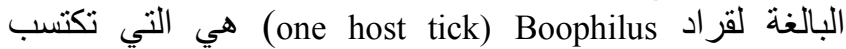

الاصابة - (الإنة

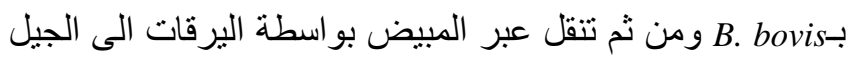

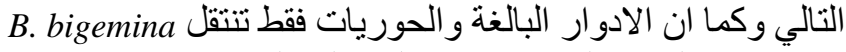

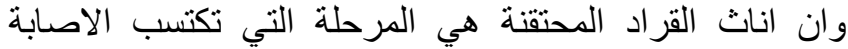




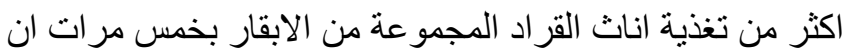

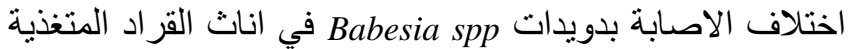

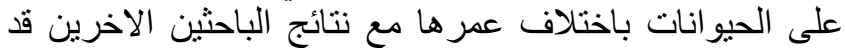

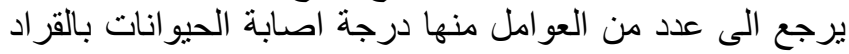

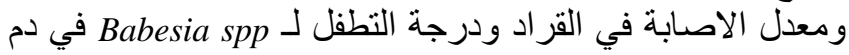

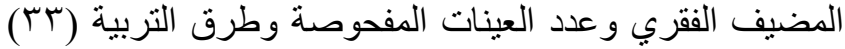

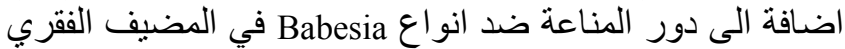

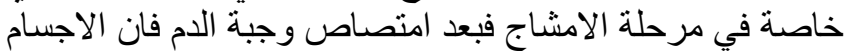

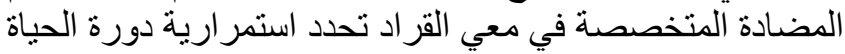

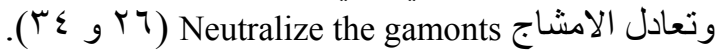

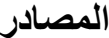

1. Uilenberg G, International collaborative research : significance of tick-borne hemoparasitic diseases to world animal health. Vet Parasitol. 1995;57(1-3):19-41.

2. Vidotto O, Andrade GM, Amaral CHS, Barboses CS, Freire RI, Rocha MA, Vidotto MC.Frequencia de anticorpos contra Babesia bigemina Babesia bovis, Anaplasma marginale emrebanhos bovines naregiao Londrina Parana. Arq Bras Med Vet Zootec. 1997;49:655659.

3. Mugisha AA, MacleodR, Percy and Kyewalabye. Strategies, effectiveness and rationale of vector-borne disease control in the pastoralist system of South-western Uganda. Trop Anim Health Prod. 2005;37(6):479-489.

4. Aktas M, Dumanli N, Karaer Z, Cakmak A, Sevgili M, ElazigNorval RAI and Mason CA.The ticks of Zimbabwe.the life cycle, distribution and hosts of Rhipicephalus simus Koch, 1844, Zimbabwe Vet J. 1981;12: 2-9.

5. Riek RF.The life cycle of Babesia bigemina (Smith and Kilborne,1893) in the tick vector Boophilus microplus (canestrini). Aust J Agricul Res. 1964;15: 802-821.

6. Rek RF. The cycle of Babesia argentina (I. gnieres, 1903) (Sporozoa : Piroplasmida) in the tick vector Boophilus microplus (canestrini). Aust J Agric Res.1966;17:247-254.

7. Callow LL and Hoyte HMD.Transmission experiments using Babesia bigemina ,Theileria mutans.Borrelia spp, and the tick Boophilus microplus. Aust Vet J.1961:381-39.

8. Callow LL. The infection of Boophilus microplus with Babesia bigemina.Parasitol. 1968:663-670.

9. Mackenstedt U, Gauer M, Fuchs P, Zopp F, Schein E, Mehlorn H. DNA measurements reveal differences in the life cycles of Babesia bigemina and $B$. canis, two typical members of the genus Babesia. Parasitol Res.1995;81:595-604.

10. Urquhart GM, ArmourJ,Duncan JL, Dunn AM, Jennings FW. Veterinary Parasitology. $2^{\text {nd }}$ ed., Black Well Science 2003;pp:242245.

11. Wall R, and Shearer D. Veterinary Ectoparasites : Biology, Pathology and control. $2^{\text {nd }}$. Edition Blackwell Science Ltd., Osney Mcad. Oxford.2001:9-10

12. Johns R, Sonenshine DE, Hynes WL. Identificiation of a defnsin from the hemolymph of the American dog tick Dermacento rvariabilis. Insect Biochem Mole Biol.2001;31:857-865.

13. Ristic M and Kreier V. Babesiosis,. Academic Press London. 1981: 358-361.

14. Brossard M and Wikel SK. Tick immunobiology Parasitol. 2004; 129 suppl. S161-176.

15. Machackova M, Obornik M, Kopecky J. Effect of salivary gland extract from Ixodes ricinus ticks on the proliferation of Borrelia burgdorferisensustricto in vivo. Folia Parasitol. 2006 ; 53:153-158.

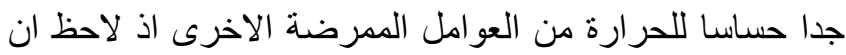

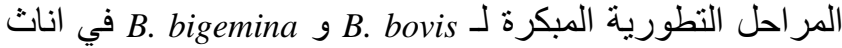

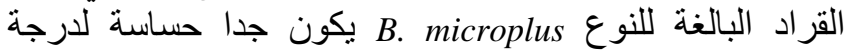

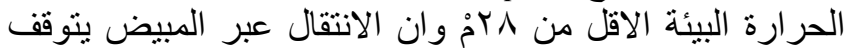

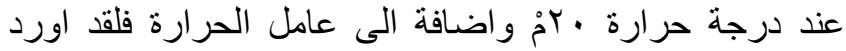

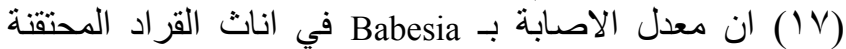

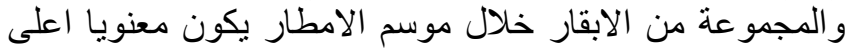

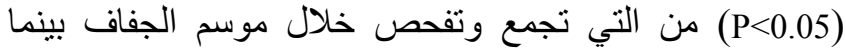

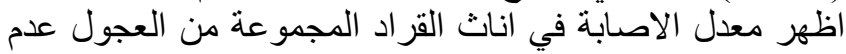

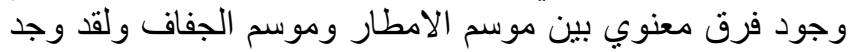

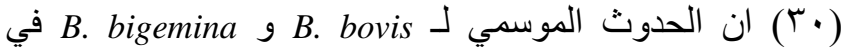

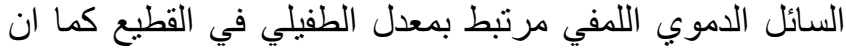

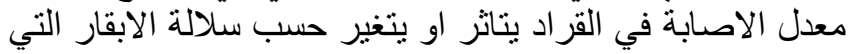

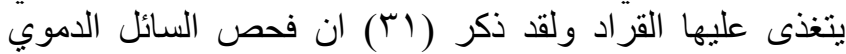

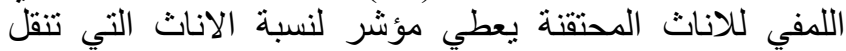

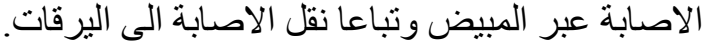

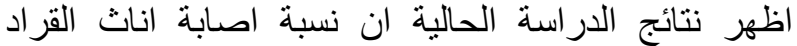

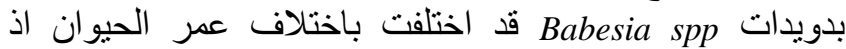

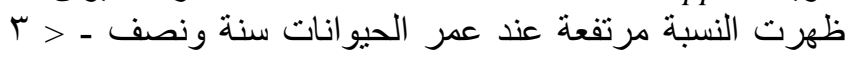

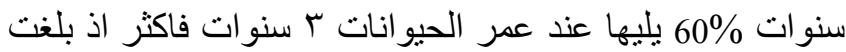

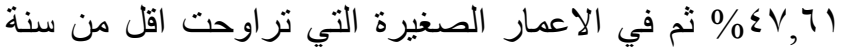

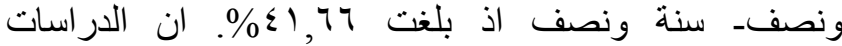

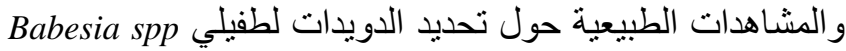

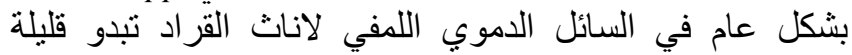

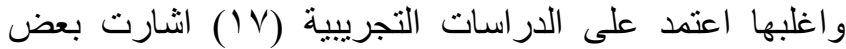
الدراسات ان عمر الحيوان قد يتداخل بطرق مختلفة في الإندابة

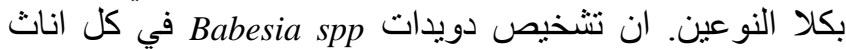

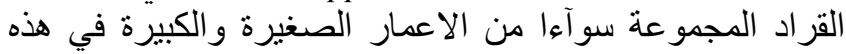

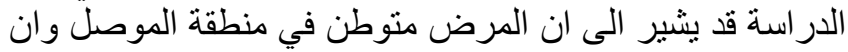

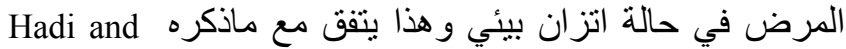

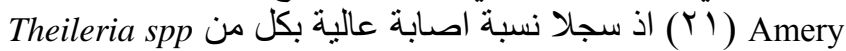

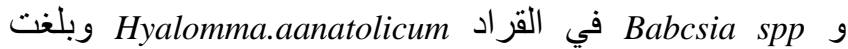

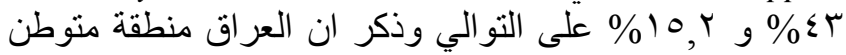

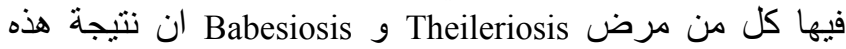

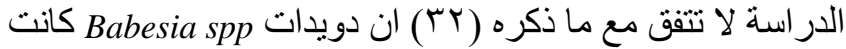

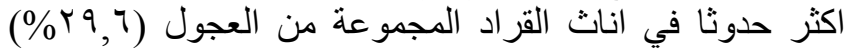

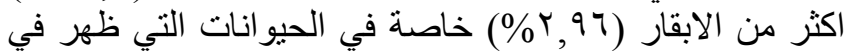

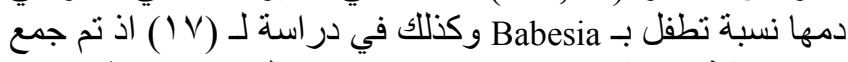

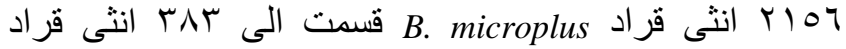

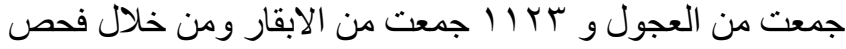
السائل الدموي اللمفي لجميع الاناث تبين الن الإنات الاصنابة الكلية

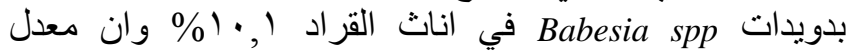

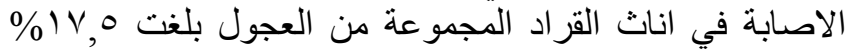

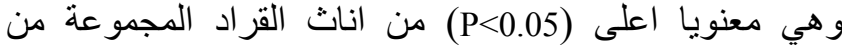
الابقار ووجد ان تغذية اناث القراد المجموعة من العجول كانت 
25. Soulsby EJL.Helminths, arthropds and protozoa of domesticated animals. $7^{\text {th }}$ ed., Philadelphia, BailliereTindall, London, 1986;707-718

26. FriedhoffKT.Interaction between parasite and tick vector. Int $\mathrm{J}$ Parasitol.1990;20:525-535.

27. Mahoney DF and Mirre GB. Babesia argentina :The infection of splenctomized calves with extracts of larval ticks (Boophilus microplus ) Res Vet Sci.1974;16:112-114

28. Potgieter FT, ELS HJ. An electron microscopic study of intraerythrocytic stages of Babesia bovis in the brain capillaries of infected splenenctomized calves. Onderstepoort J Vet Res. 1976;46:41-49.

29. Hodgson JL, StillerD, JasmerDP, BueningGM,Wanger.Nymphal and adult Boophilus microplus using DNA Probe. Parasitol 1992;74:117126.

30. JohastonLAY.Eipedemiology of bovine babesiosis in northern Queen land. Aust Vet J.1967;43:427-431

31. Mahoney DFandMirre GB. Bovine Babesiosis: estimation of infection rates in the tick vector Boophilus microplus (Canestrini). Annals Trop Med Parasitol J. 1971;65:309-317.

32. Oliveira MCS, Oliveira TCG, Jr A, Amarante AFI, Oliveira HN. Babesia spp. infection in Boophilus microplus engorged females and eggs in Sao Paulo State, Brazil Vet Parasitol. 2005;130:61-67.

33. Fridhoff KT and Smith RD.Transmisstion of Babesia by ticks. 1981.In Ristic M, Kerier JP (eds), Babesiosis, Academic Press ,San Diego. p:267-321

34. Lal AA, Patterson PS, Sacci JB, Vaughan JA, Collins WE, Wirtz RA, Azad AB. Anti-mosquitoes midgut antibodies block development of Plasmodium falciparum and Plasmodium vivax in multiple species of Anopheles mosquitoes and reduce vector fecundity and survivorship..Proc Natl Acad Sci USA. 2001;98:5228-5233.
16. Patton TG, Dietrich G, Brandt K, Dolan MC, Piesman J, Gilmore RD, Saliva, salivary gland and hemolymph collection from Ixodes scapularis ticks. JVE Immunol Infect. 2012;60:1-13.

17. Quintao-Silva MG, and Ribeiro MFG. Infection rate of Babesia spp. Sporokinetes in engorged Boophilusmicroplus from an area of enzootic stability in the state of Minas Gerais, Brazil Mem Inst Oswaldo Gruz. 2003;98(8):1-6

18. Tavassoli M, Tabatabaei M, Mohammadi M, Esmaeilinejad B, Mohamad Pour H. PCR-based detection of Babesia spp. Infection in collected ticks from cattle in west and north-west of Iran. J ArthropodBorne Dis. 2013;7(2):32-238.

19. Burgdorfer W., Hemolymph test. A technique for detection of rickettsiae in ticks. Am J Trop Med Hyg. 1970;191:1010-1014.

20. Akinboade OA and Dipeolu OO. Detection of Babesia bovis infection in Boophilus geigyi with egg crushings ,larval smears and haemolymph puncure.Veterinary Quarterly.1981;3:3:143-147

21. Hadi AMand Al-Amery AMA. Isolation of Theileria and Babesia from gut and ovary of Hard ticks Hyalomma anatolicum in Baghdad. Diyla Agricul Sci J. 2012; 4(2): 1-8.

22. Guglielmone AA, Gaid AB ,Mangild AJ. Light microscopy diagnosis of Babesia bovis and Babesia bigemina kinetes in the hemolymph of artificially infected Boophilus microplus engorged female ticks. Vet parasitol. 1996;61(1-2):15-20.17.

23. Petrie WP. Statistics for veterinary and animal science. Blackwell Science.London.2003;101-113

24. Walker A, Bouattour A, Camicas I, Estrado Pena A, Horak IG, Latif AA, PergramR G, Preston PM. Ticks of domestic animals in Africa. A guide to identification of species Bioscience Reports. Comiston Drive, Edinburgh EH105QR., Scotland UK., 2003. 